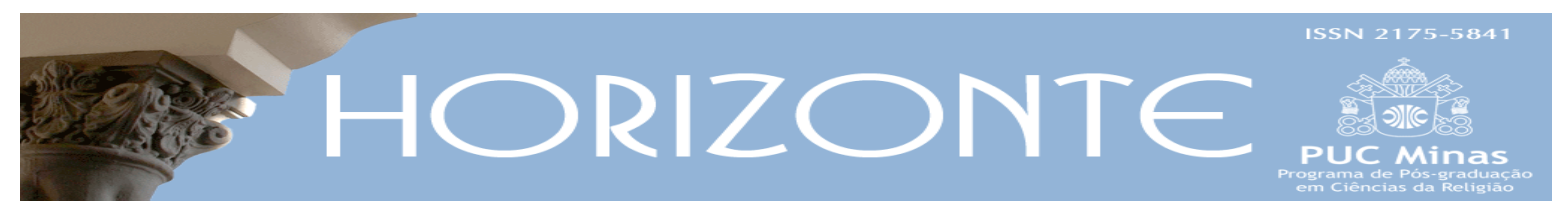

Dossiê: Narrativas Sagradas e Linguagens Religiosas - Artigo Original ๑。

\title{
Para o estudo da tradição bíblica manuscrita: uma nova proposta para o estudo do códice 2437
}

\author{
For the study of the manuscript biblical tradition: \\ a new proposal for the analysis of codex 2437
}

Anderson de Oliveira Lima*

\begin{abstract}
Resumo
$\mathrm{O}$ artigo que apresentamos à Revista Horizonte propõe um novo caminho para o estudo do códice 2437, um manuscrito em língua grega escrito entre os séculos XII e XIII que traz os quatro evangelhos do Novo Testamento canônico. O interesse por este documento é crescente e se justifica por ser ele parte do acervo da Biblioteca Nacional do Rio de Janeiro, sendo considerado o mais antigo manuscrito existente na América Latina. Trata-se, portanto, de um patrimônio cultural e material que devemos preservar e conhecer. O novo caminho sugerido pretende complementar os estudos tradicionais da crítica textual com um referencial metodológico que foi extraído da História da Cultura Escrita e dos estudos literários contemporâneos, áreas do conhecimento que nos incentivam a tomar este e outros livros não apenas para lidar com seus conteúdos, mas também para considerar alguns aspectos de sua materialidade, os diferentes paratextos neles inclusos e a história de seus usos e leituras.
\end{abstract}

Palavras-Chave: Interpretação bíblica; História da cultura escrita; Materialidade da Literatura; Códice 2437.

\begin{abstract}
This article submitted to Horizonte Journal proposes a new way to study the codex 2437, a manuscript written in Greek between the centuries XII and XIII that brings the four Gospels of the canonical New Testament. The interest in this document is growing and it can be justified because it is part of the collection of the National Library of Rio de Janeiro, being considered the oldest manuscript in Latin America. The manuscript is, therefore, a cultural and material heritage that we need to preserve and study more. Our suggestion for the research aims to complement the traditional studies of textual criticism with a methodological framework that was extracted from the History of Writing Culture and contemporary literary studies, fields of knowledge that encourage us to take books not to deal only with its contents, but also to consider some aspects of materiality, paratexts and the history of their uses and readings.
\end{abstract}

Keywords: Biblical interpretation; History of writing culture; Materiality of literature; Codex 2437.

\footnotetext{
Artigo recebido em 05 de agosto de 2015 e aprovado em 08 de junho de 2016.

* Doutor em Ciências da Religião pela Universidade Metodista de São Paulo (UMESP), doutor em Letras pela Universidade Presbiteriana Mackenzie (UPM) e especialista em Bíblia (Lato-Sensu) pela Universidade Metodista de São Paulo (UMESP). País de Origem: Brasil. Email: anderson.angela.lima@gmail.com
}

Horizonte, Belo Horizonte, v. 14, n. 42, p. 284-314, abr./jun. 2016 - ISSN 2175-5841 


\section{Introdução}

Este artigo procura apresentar uma nova proposta para o estudo da tradição bíblica manuscrita. Ele elege um objeto de estudo incomum (ao menos no campo brasileiro de pesquisas bíblicas), um códice em língua grega contendo os quatro evangelhos canônicos que foi produzido por volta do século XII. Para a análise desse tipo de objeto há várias abordagens possíveis; os caminhos mais comuns partem à paleografia, à tradução, à comparação entre este e outros manuscritos bíblicos, à identificação e avaliação das variantes textuais etc. Essas abordagens são sempre necessárias a partir do momento em que um novo manuscrito antigo é descoberto; nos permitem conhecer o documento abrem os caminhos para outras pesquisas. É aí, neste segundo momento da história dos estudos desse novo manuscrito, que nosso trabalho se insere, tendo o objetivo de estimular e dar início a uma nova fase de estudos em torno do códice 2437, documento que, como veremos, possui especial importância no cenário brasileiro.

No primeiro item do artigo vamos apresentar o códice ao leitor e depois, no item 2, vamos demonstrar, por meio de uma pesquisa bibliográfica, que competentes pesquisadores têm dado conta das primeiras etapas do trabalho de análise desse códice. Então passaremos à nossa proposta propriamente dita, que emprega ferramentas dos estudos literários e da história cultural para sugerir um novo caminho para o estudo deste objeto e de outros semelhantes. Este artigo, escrito especialmente para a revista Horizonte, é parte inicial de uma pesquisa mais extensa que atualmente estamos desenvolvendo no pós-doutorado do Programa de Pós-Graduação em Ciências da Religião da Pontifícia Universidade Católica de Campinas.

\section{0 códice 2437}

Falando do manuscrito, segundo consta no Livro de Registros da Biblioteca Nacional, ele foi doado à biblioteca por um diplomata brasileiro e ali registrado em 
24 de maio de 1912 (PINHEIRO, 2002, p. 10). Em geral os pesquisadores concordam que ele deve ter sido produzido entre os séculos XII e XIII (ALAND; ALAND, 2009, p. 236-237; SARAIVA, 2011, p. 100-118), o que faz dele o manuscrito mais antigo na América Latina.

Em 1952 Bruce M. Metzger, famoso estudioso dos manuscritos do Novo Testamento, visitou o Brasil e analisou tal códice, permitindo que ele fosse repertoriado entre os demais manuscritos gregos do Novo Testamento sob o número 2437. Nesta ocasião o códice foi enquadrado entre as cópias da categoria V pelos especialistas da Crítica Textual do Novo Testamento (ALAND; ALAND, 2009, p. 257), o que significa que o texto grego que ele traz é predominantemente do tipo bizantino (ou majoritário), que foi o tipo de texto bíblico mais copiado ao longo da Idade Média, embora hoje tenha seu valor questionado quando o que se procura é um maior grau de fidelidade aos autógrafos perdidos. ${ }^{1}$

Em 1996 o códice 2437 passou por um processo de restauração na Biblioteca Nacional e em seguida se tornou o alvo da atenção de alguns pesquisadores brasileiros que se dedicaram à sua datação, à sua descrição precisa e à produção de edições paleográficas dos quatro evangelhos, acrescidas de notas críticas sobre as diferenças dele em relação à edição grega do Novo Testamento de Nestle-Aland (1993). Extraindo as informações descritivas dos trabalhos desses pesquisadores, sabemos que o códice, escrito em grego e em letras minúsculas, contém apenas os quatro evangelhos canônicos. Indo mais fundo na descrição de sua forma, notou-se que o texto está distribuído em 31 fascículos que perfazem 233 fólios (PINHEIRO, 2002, p, 12), mas que foram perdidos os primeiros dois fascículos que continham a primeira parte do Evangelho de Mateus. Assim, segundo a numeração de capítulos

\footnotetext{
${ }^{1} \mathrm{O}$ texto do tipo bizantino teria nascido de uma revisão de textos mais antigos, iniciativa comumente atribuída a Luciano de Antioquia, no começo do quarto século. Adotado por João Crisóstomo (347-407 EC) o texto logo se popularizou em Constantinopla e alguns séculos depois se tornou o mais copiado, motivo pelo qual é também chamado de texto majoritário (PAROSCHI, 1993, p. 87). Quanto a suas características, lemos as palavras de Wilson Paroschi: "O texto bizantino tem como característica suavizar qualquer aspereza de linguagem, polir o estilo, acrescentar breves interpolações para facilitar a interpretação, combinar dois ou mais textos em forma expandida e, além disso, harmonizar passagens paralelas. Reúne, portanto, elementos comuns aos textos alexandrino, ocidental e cesareense, chegando mesmo, tanto quanto possível a combiná-los numa única narrativa, só que mais bem elaborada, mais completa, mais fácil, e com certo ar de elegância acadêmica" (PAROSCHI, 1993, p. 88).
}

Horizonte, Belo Horizonte, v. 14, n. 42, p. 284-314, abr./jun. 2016 - ISSN 2175-5841 
e versículos atualmente aceita, o texto de 2437 só começa em Mateus 9.17 (BRANDÃO, 2002, p. 43-45). Também é sabido que o códice foi composto com folhas de couro de baixa qualidade, mas os últimos quatro fólios já foram escritos em papel e apresentam sinais de uma escrita mais recente (SARAIVA, 2003, p, 13).

\section{Uma História da Pesquisa}

A primeira análise do manuscrito de que se tem conhecimento foi aquela realizada por Bruce M. Metzger. Sua análise, de caráter descritivo, foi publicada em um artigo de 1952 com o título Um manuscrito grego dos quatro Evangelhos na Biblioteca Nacional do Rio de Janeiro. As observações de Metzger foram importantes para que o manuscrito fosse incluído no rol dos códices gregos do Novo Testamento conhecidos ao redor do mundo. No ano seguinte, seguindo as informações passadas por Metzger, Kurt Aland atribuiu ao manuscrito o número 2437 e, desde então, o códice foi mencionado em vários trabalhos que tinham como tema os manuscritos gregos do Novo Testamento (BENÍCIO, 2004, p. 83-84). Entretanto, foi só em meados da década de 1990 que o códice despertou o interesse de pesquisadores brasileiros que dariam início a uma nova e frutífera fase de estudos.

A primeira iniciativa dessa nova fase parece ter sido tomada por Jacyntho Lins Brandão, que não só começou a analisar e divulgar o manuscrito como arrebanhou outros pesquisadores para o mesmo tema através de um projeto de pesquisa na Universidade Federal de Minas Gerais. Para apresentar algumas de suas contribuições vamos resumir o conteúdo de um dos artigos que ele escreveu: trata-se de $O$ códice 2437 do Novo Testamento grego (evangelho grego da Biblioteca Nacional do Rio de Janeiro), publicado em 2002. Neste trabalho Brandão demonstrou ter consciência de estar retomando a pesquisa que esteve praticamente parada desde a década de 1950. Ele declara seu objetivo 
explicitamente, que era "retomar a descrição do documento, detalhando e corrigindo as informações de Metzger", porém, restringindo-se aos "aspectos materiais e organizacionais do códice” (2002, p. 39-40). Brandão tratou das características físicas do manuscrito falando da encadernação, da escrita em letras minúsculas, dos sinais de diferentes fases de restauração, dos sumários e títulos, do estado dos fascículos etc. Também abordou elementos mais específicos, como a ausência das primeiras páginas e a inexistência dos fólios relativos aos textos de João 17.18-18.3 e 20.11-20.25 (2002, p. 43-46).

Outra contribuição significativa para a nova fase de pesquisas sobre o códice veio pelas mãos de Ana Virgínia Pinheiro, a qual se apresenta como "Bibliotecária da Fundação Biblioteca Nacional”. Ela publicou nos Anais da Biblioteca Nacional um artigo intitulado $O$ evangelho manuscrito em grego existente no acervo da Biblioteca Nacional Brasileira: aspectos codicológicos. Foi Pinheiro quem informou os pesquisadores da nova geração sobre a procedência conhecida do manuscrito citando o Livro de Registros da Seção de Manuscritos da Biblioteca Nacional de 1903-1938 (2002, p. 10). Foi ela quem expôs a história do manuscrito na Biblioteca Nacional destacando o processo de restauração pela qual o códice passou em 1996 (2002, p. 11) e descreveu com detalhes a estrutura física do documento fascículo a fascículo (2002, p. 11-16).

A partir das análises descritivas de Brandão e Pinheiro começaram a aparecer nos meios acadêmicos o resultado de outros trabalhos realizados pelos pesquisadores que seguiam Jacyntho Lins Brandão em seu grupo de pesquisas. Dentre eles, merece destaque Maria Olívia de Quadros Saraiva que dedicou seus estudos de pós-graduação (mestrado, concluído em 2001, e doutorado, em 2011) à análise do códice 2437. As conclusões expostas em sua dissertação de mestrado aparecem resumidas em $O$ Evangelho de Mateus no Manuscrito Grego da Biblioteca Nacional do Rio de Janeiro (Folha 24 recto - Mt, 18:32-35; 19:1-5), artigo de 2003. A experiência com o estudo do Evangelho de Mateus conduziu Maria Olívia de Quadros Saraiva a um novo trabalho de importância ímpar neste 
campo de pesquisas; trata-se da tese doutoral defendida em 2011: O Evangelho de Lucas no manuscrito grego da Biblioteca Nacional do Rio de Janeiro (cód. 2437): edição e glossário. Este é, além de mais recente, provavelmente o trabalho mais importante que já se produziu sobre o códice 2437. Resumindo-o, a pesquisadora dedicou o primeiro capítulo de sua tese à história do Novo Testamento grego, abordando questões relativas à origem dos textos, à sua transmissão e aos principais manuscritos de que a crítica textual hoje dispõe (2011, p. 16-44). É no segundo capítulo que ela passa a tratar especificamente do códice descrevendo-o a partir dos trabalhos anteriores e lhes acrescentando uma importante descrição de seus aspectos paleográficos, além de se aprofundar no exame do Evangelho de Lucas (2011, p. 45-119). Partindo do estudo acurado do tipo de letras gregas empregado pelo copista Saraiva desenvolve a hipótese segundo a qual o manuscrito deve ter sido produzido entre a segunda metade do século XII e início do XIII (2011, p. 100-118). O terceiro capítulo traz a cuidadosa edição paleográfica do Evangelho de Lucas (2011, p. 120-274).

Outro pesquisador envolvido com os estudos do códice é Paulo José Benício. Como os já citados, Benício publicou trabalhos em que descreveu o manuscrito apresentando-o àqueles que o desconheciam (BENíCIO, 2004), mas o papel mais relevante que lhe coube foi o estudo do texto do Evangelho Segundo Marcos. Ele se dedicou a pontos distintos do evangelho em diferentes artigos científicos, além de ter defendido sua tese doutoral sobre o tema em 2002. Destacamos Característica literárias e tendências manuscritológicas do Evangelho Segundo Marcos no códice 2437, artigo de 2011 em que o autor analisa variantes textuais e reafirma a ligação deste códice com a tradição manuscrita bizantina.

Outro nome a ser citado é o de Loide Melo de Araújo Silva que também dedicou sua pesquisa doutoral ao códice 2437, mas com foco sobre o texto do Evangelho Segundo João. O título deste trabalho de 2008 é: Evangelho de João no códice 2437: um estudo crítico-textual. A autora dividiu sua tese em duas partes: na primeira se dedicou à crítica textual de um modo geral, abordando sua história e 
princípios de utilização, e lidou com a tradição manuscrita do Novo Testamento (2008, p. 29-66). Na segunda parte ela apresentou um capítulo com a "transcrição diplomática" do texto de João, sua tradução para o português com aparato crítico (2008, p. 77-392), e outro com análises do mesmo aparato em relação a passagens selecionadas (2008, p. 393-402).

Pode-se considerar um marco para esse estágio de pesquisas a publicação, em 2012, do livro Manuscrito Grego 2437 da Biblioteca Nacional: pesquisas desenvolvidas de 1952 a 2012. Nele, as autoras Maria Olívia de Quadros Saraiva e Tereza Virginia Ribeiro Barbosa apresentam breves resumos de praticamente tudo o que se escreveu sobre o manuscrito de 1952 até aquele momento, dando nova visibilidade aos trabalhos já publicados e oferecendo a novos pesquisadores um instrumento facilitador para a fase inicial de pesquisas sobre o códice. Além disso, as autoras incluíram no livro dois capítulos alheios, um sobre a crítica textual no contexto brasileiro, de José Américo Miranda (2012, p. 19-28), e outro sobre a importância de Carlos Magno e do Império Carolíngio para a tradição manuscrita, de Viviane Cunha (2012, p. 31-37).

Por fim, antes de nossa pesquisa a própria Biblioteca Nacional do Rio de Janeiro sediou um seminário que tinha o códice 2437 como tema principal. O evento, realizando entre os dias 13 e 15 de Agosto de 2014, foi intitulado: Manuscrito Grego da Biblioteca Nacional: crítica textual e práticas de edição de texto. A organização do evento foi da já citada Maria Olívia de Quadros Saraiva que, na ocasião, também participou de maneira direta ao oferecer minicursos sobre o códice. $^{2}$

\footnotetext{
2 O anúncio do seminário está no blog da Biblioteca Nacional: <https://blogdabn.wordpress.com/2014/08/12/manuscrito-2437-o-
} manuscrito-grego-da-fundacao-biblioteca-nacional/>. Acesso em 06/08/2015. 


\section{Justificativas para Novas Abordagens da Tradição Bíblica Manuscrita}

Tendo feito contato com os trabalhos de pesquisadores que nos precederam nas análises do códice 2437 estamos em condições de nos inserir nessa história. Optamos por um caminho diferente de todos aqueles que foram trilhados, e é por isso que começaremos defendendo outras maneiras de se trabalhar com a tradição bíblica manuscrita, justificando, com isso, nossa própria abordagem.

Há apenas alguns séculos os artefatos deixados pelos homens do passado eram compreendidos como curiosidades, objetos de antiquários, peças de decoração etc. Foi quando o desenvolvimento da arqueologia (uma ciência que no início se caracterizava pelo caráter aventureiro de exploradores que viajavam em busca de artefatos raros, e que por um bom tempo foi tratada como uma ciência auxiliar de outras áreas das ciência humanas (FUNARI, 2014, p. 13-18)) deu novo destaque ao estudo da cultura material. Com o passar do tempo os objetos que agentes sociais do passado usaram, modificaram e interpretaram se transformaram em patrimônios culturais, heranças que deviam ser tomadas como pontos de partida para a produção de significados. Desse modo, tais artefatos passaram a ser cada vez mais dignos de estudo e preservação (FUNARI, 2011, p. 85; FUNARI; CARVALHO, 2009, p. 7-8).

Desde esse período os manuscritos bíblicos se transformaram em verdadeiros tesouros. Com eles, devido à inexistência dos autógrafos, julgava-se que talvez fosse possível avaliar as Bíblias que líamos e, quiçá, encontraríamos informações mais seguras sobre as origens históricas dos judaísmos e cristianismos. Por isso o século XIX testemunhou o desenvolvimento substancial de uma arqueologia bíblica, disciplina que tanto servia à curiosidade científica quanto aos interesses religiosos de seu tempo. Então os manuscritos bíblicos foram desejados e procurados como nunca, depois estudados por uma crítica textual extremamente especializada que se empenhava por reconstruir os textos em seus idiomas de origem, o que era feito a partir da comparação cada vez mais rigorosa 
entre os testemunhos manuscritos que outros especialistas escavaram, dataram, decifraram, classificaram... O resultado desse criterioso labor da crítica textual foi a publicação de edições cada vez mais completas dos textos bíblicos em hebraico e grego, acrescidos de um complexo aparato crítico com dados sobre a comparação entre as variantes textuais e as opções dos editores. Até hoje é a partir dessas edições, seguidamente revisadas e atualizadas, que se produzem as traduções vernáculas para a leitura religiosa e popular; assim os críticos especializados nos textos bíblicos podem trabalhar com os documentos em seus idiomas originais, em versões que se aproximam, tanto quanto possível, de seus originais perdidos.

Está claro que a descoberta do códice 2437 foi tardia dentro dessa longa história. Apesar de ser antigo, ele não é tão raro quanto se pode imaginar quando avaliado de um ponto de vista global. Deveras, ele é apenas mais um dentre os milhares de minúsculos que foram produzidos entre os séculos IX a XVI hoje conhecidos, ${ }^{3}$ pelo que sua análise aprofundada é uma atividade que nunca foi tratada como prioridade pelos especialistas mais capacitados para o estudo da tradição bíblica manuscrita:

a maioria dos minúsculos ainda não foi examinada por seu valor textual (pelo menos a metade deles certamente são subestimados) simplesmente porque o exame de 2812 manuscritos está além da capacidade de qualquer erudito, ou mesmo de uma equipe de eruditos. (ALAND; ALAND, 2009, p 215).

Os estudos brasileiros que conhecemos no item anterior vieram para sanar nossa ignorância quanto a um desses minúsculos, o códice 2437, mas isso dificilmente tornará nosso manuscrito um documento conhecido internacionalmente e tão relevante quanto as cópias mais antigas para a maioria. Dissemos que o códice 2437 traz apenas os quatro evangelhos e que é cópia de um texto bíblico do tipo bizantino. Julga-se pouco provável que alguma variante nele presente tenha relevância para a crítica textual do Novo Testamento, ou que o texto

\footnotetext{
${ }^{3} \mathrm{~A}$ maioria dos manuscritos antigos conhecidos do Novo Testamento estão entre estes minúsculos dos século IX a XVI. O minúsculo mais antigo de que se tem conhecimento é o códice 461, do ano 835 (SARAIVA, 2011, p. 23).
}

Horizonte, Belo Horizonte, v. 14, n. 42, p. 284-314, abr./jun. 2016 - ISSN 2175-5841 
que apresenta dos evangelhos digam algo novo sobre os cristianismos antigos. Ou seja, os críticos textuais não têm tantos motivos para tirar o códice 2437 da gaveta; os historiadores possuem documentos mais antigos e supostamente mais fiéis às origens históricas dos cristianismos; os exegetas já contam com um texto grego criticamente constituído e não teriam qualquer necessidade de dedicar tempo ao estudo desse texto especificamente. Portanto, ao eleger como objeto de estudos o códice 2437, um manuscrito bíblico do século XII, se nossos estudos ficarem limitados aos antigos métodos, imaginamos que não irão muito além do que já foi feito pelos pesquisadores brasileiros que estudaram o códice nas últimas décadas, assim como terão pouco a acrescentar aos conhecimentos já adquiridos pelas ciências bíblicas nos últimos séculos.

Diríamos que atualmente a história da pesquisa do códice 2437 vive um momento decisivo. Ou a pesquisa toma novos rumos ou um ciclo de trabalhos se encerrará sem previsões para ser retomada. A questão é: o que fazer a partir desse ponto? Será que não há mais nada para dizer sobre o códice 2437 nesta geração?

\section{Crítica Literária e História do Livro}

Em busca de novas alternativas analíticas nossa proposta é, primeiramente, abordar o códice 2437 num trabalho de reconhecimento do valor cultural deste que, como patrimônio da Biblioteca Nacional do Rio de Janeiro, é o mais antigo texto existente em terreno latino americano (SARAIVA, 2011, p. 12). Assim, anunciamos nossa pesquisa como quem quer lidar com uma parte do acervo cultural da humanidade que nosso país tem o privilégio de possuir e o dever de preservar, conhecer e divulgar. Visto individualmente, e não como parte de um gigantesco projeto que tem como objeto a literatura bíblica, o estudo do códice 2437 pode ser encarado como um típico trabalho de valorização de nossa cultura 
material, ${ }^{4}$ o que torna a pesquisa justificável independentemente dos interesses dos biblistas.

Em segundo lugar propomos que se leve em conta as especificidades desse objeto que é, antes de qualquer outra coisa, um livro antigo. Isso quer dizer que não nos importaremos apenas com os conteúdos bíblicos, mas com o códice como o suporte material escolhido para a transmissão desse conteúdo e com os efeitos que essa materialidade transmite ao leitor. Não devemos trabalhar com o manuscrito como se o conteúdo bíblico nele inscrito pudesse se comunicar de maneira independente de sua materialidade, como se as ideias nele expressas fossem imutáveis e pudessem nos ligar à mente do autor sem qualquer tipo de mediação. E para dar conta desse aspecto material do códice na produção de sentidos nós empregaremos um novo referencial teórico:

Roger Chartier é um pesquisador francês que trabalha com a História da Cultura Escrita e tem desenvolvido modos abrangentes de lidar com os livros de uma perspectiva que une a teoria literária à história do livro e da leitura. Em um livro seu recentemente publicado no Brasil, $A$ mão do autor e a mente do editor (2014), Chartier afirma que sua disciplina deve lidar com a "pluralidade das operações usadas na publicação de textos” (2014, p. 38), o que o leva a considerar os livros produtos acabados e, inevitavelmente, de autoria coletiva. Ele defende em diferentes obras que "O processo de publicação, seja qual for sua modalidade, sempre é coletivo, já que não separa a materialidade do texto da textualidade do livro. Portanto, é inútil pretender distinguir a substância essencial da obra [...] das variações acidentais do texto [...]” (CHARTIER, 2010, p. 40; CHARTIER, 2006, p. 2).

\footnotetext{
4 "Por cultura material poderíamos entender aquele segmento do meio físico que é socialmente apropriado pelo homem. Por apropriação social convém pressupor que o homem intervém, modela, dá forma a elementos do meio físico, segundo propósitos e normas culturais. Essa ação, portanto, não é aleatória, casual, individual, mas se alinha conforme padrões, entre os quais se incluem os objetivos e projetos. Assim, o conceito pode tanto abranger artefatos, estruturas, modificações da paisagem, como coisas animadas (uma sebe, um animal doméstico), e, também, o próprio corpo, na medida em que ele é passível desse tipo de manipulação (deformações, mutilações, sinalações) ou, ainda, os seus arranjos espaciais (um desfile militar, uma cerimônia litúrgica)". (MENESES, 1983, p. 112).
}

Horizonte, Belo Horizonte, v. 14, n. 42, p. 284-314, abr./jun. 2016 - ISSN 2175-5841 
Chartier reconhece, obviamente, que todo autor emprega um conjunto de dispositivos que têm a finalidade de controlar a interpretação do texto. Há na mente de todo escritor uma leitura ideal de sua obra, e o texto possui qualidades coercitivas que buscam evitar os devaneios dos leitores e tornar a comunicação bem sucedida. Porém, por vários motivos, ele nega que o autor possa exercer pleno controle sobre a leitura que alguém faz de seu texto, e a distância entre a leitura real e a ideal já começa na produção do próprio livro que deve, para chegar ao leitor, converter ideias em signos e assumir uma existência concreta:

é preciso levar em conta que as formas produzem sentidos e que um texto, estável por extenso, passa a investir-se de uma significação e de um status inéditos, tão logo se modifiquem os dispositivos que convidam à sua interpretação. (CAVALLO; CHARTIER, 1998, p. 13).

Segundo Chartier, as instruções dadas pelo autor:

são cruzadas com outras, trazidas pelas próprias formas tipográficas: a disposição e a divisão do texto, sua tipografia, sua ilustração. Esses procedimentos de produção de livros não pertencem à escrita, mas à impressão, não são decididas pelo autor, mas pelo editor-livreiro e podem sugerir leituras diferentes de um mesmo texto. (CHARTIER, 2011, p. 97).

Roger Chartier chama os recursos empregados pelo autor e pela materialidade do texto para controlar a produção de sentidos de protocolos de leitura, um conceito que nós empregaremos com frequência para desenvolver nossa análise do códice 2437 :

todo autor, todo escrito impõe uma ordem, uma postura, uma atitude de leitura. Que seja explicitamente afirmada pelo escritor ou produzida mecanicamente pela maquinaria do texto, inscrita na letra da obra como também nos dispositivos de sua impressão, o protocolo de leitura define quais devem ser a interpretação correta e o uso adequado do texto, ao mesmo tempo que esboça seu leitor ideal [...] É possível, portanto, interrogando de novo os textos e os livros, revelar as leituras que pretendiam produzir [...] (CHARTIER, 2011, p. 20). 
Apesar de Chartier sempre se referir a livros impressos em seus exemplos, o tratamento que se pode dar a manuscritos anteriores à invenção da imprensa não é muito diferente. Os processos de produção pelos quais o manuscrito grego da Biblioteca Nacional passou são peculiares, artesanais, típicos da produção manuscrita anterior à criação da página impressa. Todavia, o códice também traz em si dispositivos que tentam guiar seu leitor a uma leitura ideal, ou seja, também possui um protocolo de leitura.

Além dos objetivos dos autores bíblicos, responsáveis pelos quatro evangelhos que foram escritos no final do século I, o códice apresenta diversos acréscimos ao texto bíblico que, quando examinados com cuidado, indicam os objetivos de outros agentes responsáveis pela produção do livro. Há, por exemplo, a influência dos cristãos que estabeleceram o cânone do Novo Testamento e escolheram a ordem dos evangelhos, o que é, naturalmente, um modo de sugerir uma leitura que parta do Evangelho de Mateus ao de João, sequencialidade que não havia sido prevista pelos autores dos evangelhos. Há também uma leitura idealizada pelo copista do códice 2437 especificamente, o qual, a partir de seus objetivos pessoais e profissionais, de suas condições momentâneas e dos hábitos da atividade escribal de seu tempo, produziu um códice para determinados fins, para certos tipos de leituras e usos. As intervenções desse copista sobre o texto bíblico são muitas e passam pelos títulos dados aos livros, pelas ilustrações incluídas, pelas abreviações empregadas, pelas alterações (voluntárias ou involuntárias) feitas no texto recebido, pela opção de produzir um livro apenas com os quatro evangelhos, pelo acréscimo de sumários e títulos nos cabeçalhos etc.

E já que estamos sugerindo o emprego das ideias de Roger Chartier para o estudo da tradição bíblica manuscrita, devemos ir mais longe e assumir outras propostas que o historiador francês tem desenvolvido e aplicado. Além do estudo dos protocolos de leitura, ação que exige uma análise textual que não se esqueça de considerar a pluralidade dos processos de produção do livro, Chartier pergunta: 
uma história das leituras pode contentar-se com esses balizamentos nos textos e objetos impressos, com essas identificações escriturais ou tipográficas de leituras desejadas ou supostas? Evidentemente não, uma vez que cada leitor, a partir de suas próprias referências, individuais ou sociais, históricas ou existenciais, dá um sentido mais ou menos singular, mais ou menos partilhado, aos textos de que se apropria. (CHARTIER, 2011, p. 20).

Colocam-se então outros dois elementos necessários para a História da Cultura Escrita, também apontados por Roger Chartier em $A$ mão do autor e a mão do editor. Um deles é a "instabilidade dos significados" ou, noutras palavras, as relações entre os protocolos de leitura impostos por autores, editores e livros, e as inumeráveis formas de recepção dos textos por parte dos leitores empíricos (2014, p. 41-42).

Sabemos que, por mais claras e numerosas que sejam as instruções que uma obra ofereça para definir a relação correta do leitor com o texto, elas não são capazes de suprimir a liberdade criativa dos leitores. Sempre devemos considerar que o leitor é movido por fatores pessoais, psicológico, fisiológicos, por hábito de origem cultural que, em conjunto, tornarão sua recepção única, e não necessariamente correta ou equivocada:

os atos de leitura que dão aos textos significações plurais e móveis situamse no encontro de maneiras de ler, coletivas ou individuais, herdadas ou inovadoras, íntimas ou públicas e de protocolos de leitura depositados no objeto lido, não somente pelo autor que indica a justa compreensão de seu texto, mas também pelo impressor que compõe as formas tipográficas, seja com um objetivo explícito, seja inconsciente, em conformidade com os hábitos de seu tempo. (CHARTIER, 2011, p. 78).

O último objeto que Roger Chartier considera importante para a História da Cultura Escrita diz respeito às "autoridades" que, fora dos textos, também condicionam a recepção dos mesmos estabelecendo os clássicos, elegendo os gênios, determinando os gostos (2014, p. 42-46). Para uma boa exposição desse último fator tomaremos emprestadas algumas palavras de Márcia Abreu que, em Cultura letrada: literatura e leitura, escreveu: 
Para que uma obra seja considerada Grande Literatura ela precisa ser declarada literária pelas chamadas "instâncias de legitimação". Essas instâncias são várias: a universidade, os suplementos culturais dos grandes jornais, as revistas especializadas, os livros didáticos, as histórias literárias etc. Uma obra fará parte do seleto grupo da Literatura quando for declarada literária por uma (ou, de preferência, várias) dessas instâncias de legitimação. Assim, o que torna um texto literário não são suas características internas, e sim o espaço que lhe é destinado pela crítica e, sobretudo, pela escola no conjunto dos bens simbólicos. (ABREU, 2006, p. 40).

No caso dos textos bíblicos sempre devemos ter em mente que o cristianismo atua como forte mediador nos contatos dos leitores com o livro, e novamente somos forçados a ampliar nossos horizontes analíticos. Ora, se a leitura é condicionada pelo tipo de papel em que o texto está impresso, pela imagem escolhida para ilustrar a capa, pelas palavras dos paratextos ali incluídos, pela segmentação do texto em capítulos e versículos, pelo lugar onde o livro é colocado nas livrarias, pelo valor que por ele o leitor paga, pelos juízos previamente oferecidos por determinada comunidade leitora a respeito do título, pelas condições do ambiente em que a leitura se dá etc., é inegável que o cristianismo, instituição cuja autoridade a história estabeleceu na cultura ocidental, sempre exerce um forte impacto sobre cada leitor que toma uma Bíblia nas mãos. De fato, adotando a proposta analítica de Marcia Abreu (citada acima) diríamos que o cristianismo (isso sem contar sua trajetória paralela no judaísmo) é a própria instância de legitimação que deu à Bíblia o rótulo que a transformou em livro sagrado e a fez diferente de todas as demais produções literárias da humanidade. E a força desse rótulo institucional é tão grande em nosso contexto sociocultural que, na maioria das vezes, o leitor sequer imagina que possa existir uma leitura bíblica que não esteja subordinada às instituições religiosas. Como críticos, pode ser uma parte de nosso trabalho mensurar o impacto da cultura cristã em cada leitura que alguém faz da Bíblia.

Esse choque entre 1) os protocolos de leituras expressos nos próprios livros por sua textualidade e materialidade com 2) as forças mediadoras externas e 3) a inventividade ilimitada dos leitores reais podem ser vistos como ricos campos de 
pesquisas que, como sugeriu Robert Darnton, pede a união da teoria literária à história do livro, da análise textual à pesquisa empírica. ${ }^{5}$ Aí se desvendam os verdadeiros usos que os leitores fazem dos textos, aí se mostram seus hábitos de leitura, e o crítico poderá averiguar quão longe está o leitor virtual, inscrito no próprio livro, do leitor de carne e osso que é, no fim das contas, senhor da produção de sentidos (CHARTIER, 2011, p. 21). Esse é o exame do que chamaremos, sempre adotando Roger Chartier, práticas de leitura.

Assim concluímos nossa exposição do referencial teórico que estamos sugerindo para o estudo da tradição bíblica manuscrita e empregando experimentalmente na análise do códice 2437. E convém mencionar que sua aplicação já era considerada necessária para a valorização deste manuscrito, pelo menos por Ana Virgínia Pinheiro, que escreveu:

O maior interesse do códice, para o Brasil, está não só em instrumentalizar pesquisas históricas sobre a produção de registros do conhecimento na Europa medieval, mas, principalmente, por documentar práticas de leituras que se fizeram no Brasil. (PINHEIRO, 2002, p. 9).

O problema que se apresenta neste ponto é: como “documentar as práticas de leituras” do códice 2437 e preencher essa lacuna com a qual a história das pesquisas ainda não lidou? Deveras, "Reencontrar esse fora-do-texto não é tarefa fácil, pois são raras as confidências dos leitores comuns sobre suas leituras" (CHARTIER, 2011, p. 20-21). Mais difícil ainda (aparentemente impossível neste caso) é determinar o lugar em que se deram essas leituras para concluir, como Pinheiro gostaria, que elas foram feitas em território brasileiro.

Para ter acesso aos produtos da leitura concreta do códice 2437 levaremos em conta que o manuscrito não traz apenas o texto bíblico e os sinais do trabalho

\footnotetext{
${ }^{5}$ Julgando que vale a pena ler as linhas de Robert Darnton a esse respeito nós transcreveremos algumas delas nessa nota: "[...] é tempo de estabelecer uma ligação entre a teoria literária e a história do livro. A teoria pode revelar o leque de reações em potencial a um texto - isto é, às coerções retóricas que orientam a leitura que efetivamente ocorreram - isto é, dentro dos limites de um conjunto incompleto de indicações [...] Portanto, eu defenderia uma estratégia dupla, que combinaria a análise textual e a pesquisa empírica. Dessa forma, seria possível comparar os leitores implícitos dos textos e os leitores efetivos do passado, e a partir dessas comparações desenvolver uma história e uma teoria da reação do leitor" (DARNTON, 2010, p. 195).
}

Horizonte, Belo Horizonte, v. 14, n. 42, p. 284-314, abr./jun. 2016 - ISSN 2175-5841 
de um escriba, mas também outras marcas que lhe foram impostas posteriormente por alguém que o utilizou. Estamos falando de marcas de desgastes decorrentes do manuseio, de notas marginais com possíveis orientações para a leitura pública, de correções feitas entre as linhas ou às margens, de numerações de páginas diferentes, de sublinhados, ilustrações, observações sobre variantes etc. Esses sinais, que também podem ser chamados de marginalia, ${ }^{6}$ estão presentes nas páginas do manuscrito e nos servirão como indícios de leituras e usos reais do texto.

Nosso interesse pela marginalia do códice 2437 segue uma tendência dos estudos literários e culturais que têm reconhecido cada vez mais o papel do leitor como agente produtor de sentidos de importância igual à do próprio autor. Atualmente, "marginalia de todos os períodos parecem ser potenciais minas de ouro para os estudiosos" (JACKSON, 2001, p. 6) e, citando palavras de Maria do Céu Estibeira, pesquisadora que se dedica aos estudo da marginalia de Fernando Pessoa, temos:

Sempre que anota um livro, o leitor acaba por revelar algo de si próprio aquilo em que acredita, aquilo que o distrai ou que o apaixona, aquilo que o perturba ou irrita, ou até aquilo que anteriormente leu - exibindo também pormenores fascinantes relativos à época ou ao contexto em que foram produzidas as anotações e conferindo à leitura uma função interativa, na medida em que o sentido não é apenas pertença de um texto mas é reproduzido pelo leitor em conjunção com as estruturas verbais do mesmo. (ESTIBEIRA, 2010, p. 130).

Nossa proposta, portanto, é lidar com o códice 2437 o tomando como artefato produzido pela humanidade que é tanto um testemunho de determinada prática cultural do passado como um objeto que seguiu impulsionando a produção cultural de outras gerações através da complexa e peculiar atividade humana que é a leitura.

\footnotetext{
${ }^{6}$ Maria do Céu Estibeira define marginalia dizendo: “O termo marginalia, do adjetivo latino marginalis, significando 'à margem de', refere-se, portanto, aos comentários ou às notas escritas nas margens ou noutros espaços em branco junto do texto de uma página impressa, nas folhas em branco ou nas folhas de guarda de um livro e foi importado de Coleridge, o qual veio a revelar-se um mestre exímio desta técnica e a tornar-se numa referência na história da anotação" (ESTIBEIRA, 2010, p. 130).
} 


\section{A Leitura Idealizada para o Códice 2437: Protocolos de Leitura}

Passaremos às nossas análises preliminares do códice 2437 nos concentrando por hora sobre os protocolos de leitura, nos elementos contidos no próprio códice que visam controlar a recepção e conduzir o leitor a uma interpretação ideal. Assumimos que "um texto sempre se dá a ler ou escutar em um de seus estados concretos" (CHARTIER, 2010, p. 41) e, considerando nosso documento desse ponto de vista, concluímos que a comunicação que nos interessa parte não somente do texto dos evangelhos, mas, principalmente, das formas e dos paratextos que são produtos de séculos de cópias manuais dos textos bíblicos. Abordaremos nessa quinta parte de nosso trabalho alguns elementos de fácil observação no códice, além de outros que os pesquisadores que nos precederam já estudaram parcialmente. Passaremos por eles rapidamente, colhendo informações que deverão se mostrar decisivas para as próximas etapas da pesquisa.

\subsection{Só Quatro Evangelhos?}

Uma primeira questão para o estudo dos protocolos de leitura implicados no códice 2437 diz respeito à decisão do copista de produzir um livro com apenas os quatro evangelhos canônicos, dispostos na mesma sequência em que estes quatro evangelhos se encontram no Novo Testamento (Evangelhos segundo Mateus, Marcos, Lucas e João). Em poucas palavras, por que copiar apenas os evangelhos quando o Novo Testamento já era uma coleção canônica conhecida há séculos?

A razão para essa limitação pode ser simples, como a mera indisponibilidade de matéria prima, a falta de recursos para a encomenda de uma Bíblia completa por parte do comprador ou, uma hipótese mais provável, se deve uma prática de leitura cristã daqueles dias que privilegiava os evangelhos nas leituras litúrgicas e impulsionava a produção de livros apenas com os evangelhos (evangeliários). Atualmente são conhecidos vários outros códices de períodos aproximados que, como o 2437, foram copiados com letras minúsculas e contém apenas os 
evangelhos. Maria Olívia de Quadros Saraiva mencionou alguns exemplos: primeiro o códice 461, do ano 835, o mais antigo códice conhecido que traz o texto grego com letras minúsculas; depois o códice 700 do século XI (SARAIVA, 2011, p. 23-25). O que realmente importa para nossa pesquisa é que essa escolha, que seleciona uma parte do cânone e torna o livro diferente de um Novo Testamento comum, faz com que a recepção do conteúdo do códice seja peculiar.

Por exemplo, a ausência dos demais livros do cânone entre as capas do códice é um limitador para uma das mais antigas práticas de leitura bíblica, que é fragmentária, comparativa e se autolegitima. A Bíblia nasceu num mundo praticamente iletrado e sua leitura costumava ser feita em circunstâncias específicas, em que grupos se reuniam por motivos religiosos e ouviam a leitura de trechos selecionados em voz alta. E esse tipo de leitura pública não era sequencial, mas quase sempre pontual, fragmentária, ritualística. Mesmo os leitores mais especializados, fossem eles comentadores rabínicos ou pais da igreja, sempre empreendiam discussões extensas sobre pequenas unidades textuais que eram retiradas de seus respectivos contextos literários e empregadas como aforismos independentes. Em discussões mais elaboradas essas passagens, consideradas palavras de Deus e não de homens, podiam ser comparadas a outras, de modo que nessa hermenêutica religiosa elas legitimavam umas às outras sem qualquer preocupação com seus respectivos contextos literários ou origens históricas. Como escreveu Jack Miles, trata-se de:

uma tradição de leitura que considera a totalidade do texto como simultânea em si mesma, de forma que qualquer versículo pode ser lido como um comentário sobre qualquer outro versículo, e qualquer afirmação verdadeira a respeito de Deus num determinado ponto é considerado verdadeira em todos os pontos. (MILES, 2009, p. 21).

Ainda neste exemplo, consideremos o Evangelho de Mateus, que em seus primeiros três capítulos menciona com frequência passagens selecionadas dos profetas do Antigo Testamento. O procedimento é conhecido como tipologia, um método interpretativo em que "Tudo o que acontece no Antigo Testamento é um 
'tipo', um esboço antecipador de algo que acontece no Novo [...] O que se passa no Novo Testamento constitui um 'antitipo', uma forma realizada, de algo prefigurado no Antigo (FRYE, 2004, p. 108-109). O propósito do autor é defender que Jesus é o Messias que, segundo a interpretação religiosa de seu tempo, havia sido anunciado pelos antigos profetas. As relações intertextuais que estabelece demonstram a importância que o autor do evangelho dava aos textos mais antigos, incentivam de certa maneira a leitura e a preservação deles no interior dos novos grupos cristãos e evidenciam que, nos dias da composição do evangelho, a messianidade de Jesus não era um ponto pacífico da teologia judaico-cristã. Todavia, para o destinatário imaginado pelo produtor do códice 2437, que vive a partir dos séculos XII e XIII, a teologia cristã estava estabelecida; Jesus era não somente o Messias, mas o próprio Deus. O status sagrado que a igreja já atribuíra ao texto dificultava a elaboração de qualquer leitura crítica no interior dessa tradição e o leitor dos evangelhos não teria motivos para, indo aos profetas do Antigo Testamento, testar a argumentação mateana. Nisso tudo vemos com novos argumentos como a textualidade está subordinada à forma do livro e como a leitura está subordinada ao tempo e ao lugar em que se realiza; neste caso, a mediação religiosa se manifesta na forma do livro e esta, por sua vez, contribui para a criação de novos protocolos de leitura.

Entretanto, ainda que o leitor do códice 2437 não seja estimulado a fazer comparações intertextuais entre os dois Testamentos, ele é, mais do que o leitor de uma Bíblia completa, motivado a comparar os textos dos quatro evangelhos. De fato, o conteúdo do códice seria curioso se já não conhecêssemos o cânone neotestamentário. Que tipo de livro traz quatro versões diferentes da mesma história? E um agravante é que as quatro versões, se lidas sequencialmente e comparadas com atenção, revelarão uma série de incoerências entre as históricas contadas. Para um leitor moderno o efeito da leitura comparativa que a justaposição dos quatro evangelhos provoca pode ser o da implausibilidade histórica; mas, para o leitor antigo, acostumado à literatura bíblica e sua arte redacional que reúne tradições literárias de fontes distintas, talvez o efeito fosse 
outro, como o de um olhar multifocal para a história de Jesus que assim se dá a conhecer de maneira mais completa (ALTER, 2007, p. 204-205).

O que não se pode negar é que o códice 2437 acentua, mais que qualquer Bíblia completa, a importância de Jesus e seu protagonismo para a teologia cristã. Tendo-o em mãos o leitor é colocado de modo muito particular e enfático diante da vida, morte e ressurreição de Jesus, assim como de todas as implicações teológicas que essa história acarreta. Isso demonstra que, mesmo dentro de uma cultura religiosa que defende a inspiração divina por trás de dezenas de livros que formam seu cânone, uma porção seleta desses livros merece destaque. A história de Jesus, narrada quatro vezes, é um cânone dentro do cânone; aceitar essa centralidade dos evangelhos dentro das tradições literárias do cristianismo é fundamental para o leitor modelo, que atende aos protocolos de leitura do códice 2437.

\subsection{Os Títulos dos Evangelhos}

Outros elementos interessantes que precisam receber atenção em nosso estudo dos protocolos de leitura do códice 2437 são os títulos que abrem os quatro evangelhos. Sabemos pelos manuscritos mais antigos da tradição neotestamentária que os evangelhos originalmente não possuíam títulos nem quaisquer menções a seus autores. A atribuição da autoria desses livros a personagens ilustres nos mitos fundantes do cristianismo é posterior, se baseia na prática da pseudoepigrafia e serviu para legitimar os livros e seus conteúdos. Isso já demonstra, parcialmente, como tais livros foram apropriados pelas comunidades cristãs e como ganharam importância até alcançarem o status canônico definitivo. Também nos faz lembrar que livros são produtos de autoria coletiva e que as Bíblia que os homens leram durante a Idade Média e na modernidade são obras mais cristãs do que os evangelistas algum dia pretenderam.

Os títulos que abrem os evangelhos no códice 2437, portanto, devem ser recebidos como paratextos incluídos por profissionais da produção livreira, tais 
como redatores, editores, copistas etc., que procuravam, de antemão, condicionar a leitura dos livros bíblicos, atribuir-lhes maior autoridade, facilitar a aceitação dos valores ali defendidos. E novamente temos que nos lembrar que os leitores da Bíblia dos séculos XII ou XIII (destinatários para os quais o códice foi escrito) estavam inseridos numa tradição cristã milenar em que só membros do clero têm fácil acesso à Bíblia. Tais leitores dificilmente fariam distinção entre os textos originais e esse tipo de paratexto acrescidos a eles, assim como não questionariam as intenções dos mediadores institucionais que lhes ofereceram o livro na forma que o conheciam. Na recepção ideal, portanto, parte-se do pressuposto de que os evangelhos são obras de apóstolos ou de sujeitos históricos que estiveram próximos a apóstolos, e essa informação está expressa principalmente nos títulos.

Falando mais diretamente dos títulos que se leem no códice, no começo do Evangelho de Marcos, temos: "+ EUAGGELION KATA MARKON TO DEUTERO(N)" (Evangelho Segundo Marcos, o Segundo), e antes de Lucas, lemos: “TO EUAGGELION KATA LOUKAN TO(N) TRITON" (Evangelho Segundo Lucas, o Terceiro). Até aqui os títulos parecem indicar os autores e a ordem dos evangelhos no códice (Mateus, Marcos, Lucas e João), mas o título de João, que é o quarto dos evangelhos, curiosamente diz: “+ EUAGGELION KATA IWANNHN: O PRWTOS” (Evangelho Segundo João, o Primeiro).

Figura 1 - Fólio 173 recto - título do Evangelho de João no códice 2437

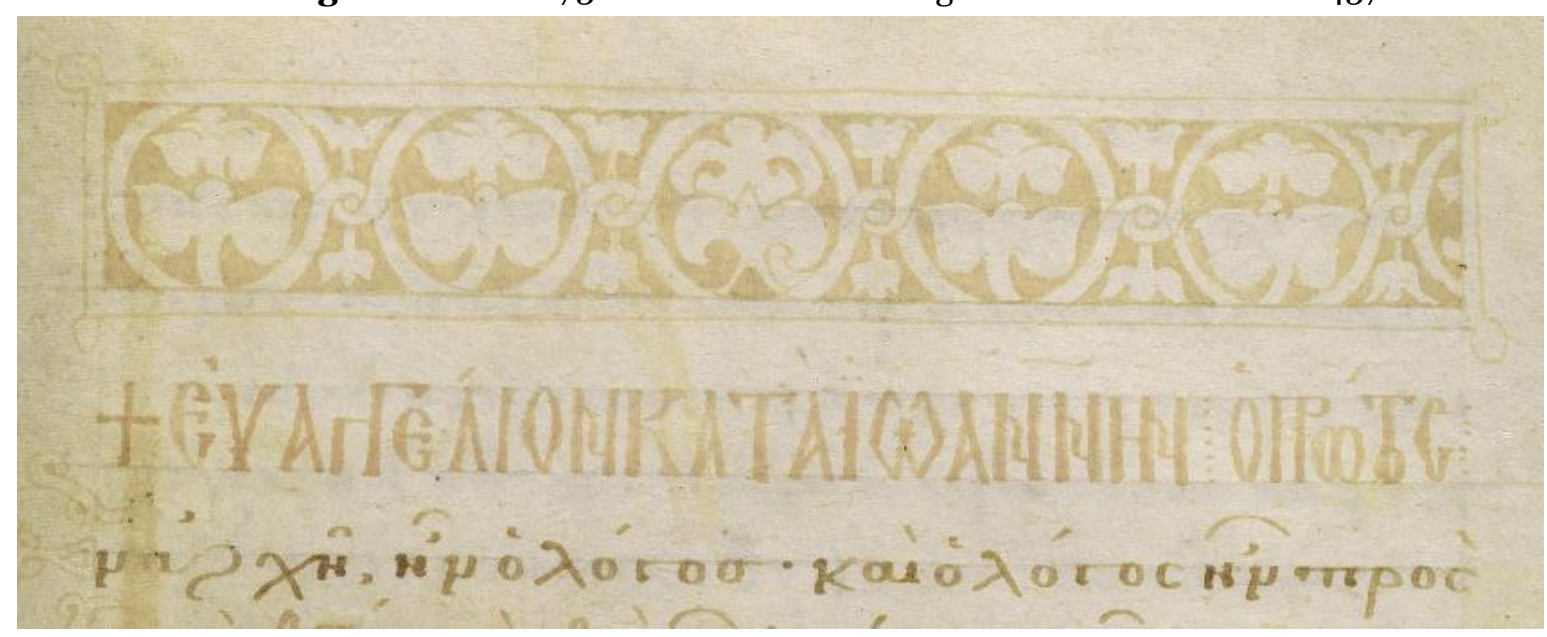

Fonte: Acervo da Fundação Biblioteca Nacional - Brasil (2015). 
Além do estranho título de João, infelizmente há partes do códice que foram perdidas e por isso não temos acesso às primeiras páginas do Evangelho Segundo Mateus para sabermos que título o copista lhe atribuiu. Jacyntho Lins Brandão, quando estudou o manuscrito, se deparou com essa questão e levantou duas hipóteses para explicar os títulos: numa delas Brandão sugeriu que os apostos não se aplicam aos evangelhos, e sim aos evangelistas. Neste caso a parte perdida de Mateus teria que dizer algo como: Evangelho Segundo Mateus, o Quarto. Os evangelistas estariam organizados na seguinte ordem: João, Marcos, Lucas e Mateus, embora os evangelhos estivessem noutra sequência no cânone. A outra possibilidade aventada por Brandão foi: "Pode tratar-se de lapso já transmitido por algum outro modelo de que 2437 derivaria” (2002, p. 51). Ou seja, talvez a parte perdida de Mateus também trouxesse o aposto o Primeiro e o título do Evangelho de João, que deveria dizer o Quarto, estaria simplesmente errado. Contudo, um equívoco tão evidente por parte dos copistas no título do quarto evangelho nos parece uma saída menos provável.

Elegendo a primeira hipótese, a de que o copista atribui aos evangelistas uma sequencialidade diferente da ordem dos livros, temos que lidar com um problema que Jacyntho Lins Brandão já apontava: "O principal, contudo, é compreender por que se aplica a João este qualitativo: o` prw/toj” (2002, p. 50). Quiçá a numeração se refira à suposta ordem em que os evangelhos foram escritos por seus autores originais ou, quem sabe, tenha mesmo o intuito de sugerir uma ordem de importância e, consequentemente, de leitura. João poderia ser chamado de primeiro se o copista, aderindo a uma tradição do cristianismo medieval, supusesse que o evangelho joanino foi o primeiro a ser escrito, ou por ser considerado o mais importante dos quatro. Neste caso faria sentido a sequência João, Marcos, Lucas e Mateus (supondo que o título perdido de Mateus o apresentaria como o quarto).

Seguindo por esse caminho notamos que o copista respeita a sequência canônica no modo como organiza os quatro evangelhos no códice, mas parece 
sugerir outra alternativa ao seu leitor, um caminho de leitura que, segundo seu juízo, seria mais fiel à história dos próprios evangelhos. Com isso os títulos poderiam ser interpretados como reguladores da leitura ideal, instrumentos coercitivos que assumem a forma de paratextos por já não ser possível modificar a sequencialidade da coleção canônica no tempo do trabalho do copista. Na leitura pressuposta que daí nós podemos tentar reconstruir, o Evangelho Segundo João ganharia um destaque especial, pareceria uma narrativa pautada na experiência pessoal de um apóstolo, talvez a mais próxima dos eventos históricos, e tudo isso induziria os leitores a preferi-lo. O Evangelho Segundo Marcos, o mais breve de todos, seria considerado um documento de fonte indireta, pois na tradição cristã Marcos teria colhido informações do apóstolo Pedro para a composição de seu evangelho. Depois, o Evangelho Segundo Marcos teria sido corrigido e aperfeiçoado, primeiro por Lucas, que por sua vez teria sido companheiro do apóstolo Paulo, e depois por Mateus, este sim um apóstolo, conforme Mateus 9.9.7 Tal seria (mas colocamos isso de maneira apenas hipotética) o protocolo de leitura implicado no códice 2437 por esses títulos paratextuais.

\subsection{Os Símbolos nos Finais dos Evangelhos}

O códice 2437 traz, no final de cada um dos quatro evangelhos, alguns símbolos que alteram a experiência do leitor e que, naturalmente, suscitam nossa curiosidade. São signos imagéticos formados pelo arranjo dado às palavras gregas (signos verbais) nas páginas que encerram cada um dos quatro livros bíblicos. Ana Virgínia Pinheiro fez um estudo preliminar desses símbolos e nós pretendemos, nessas páginas, retomar suas anotações a fim de tirarmos mais algumas conclusões sobre o protocolo de leitura do códice bíblico.

Os símbolos aos quais nos referimos seriam: uma cruz invertida no final do Evangelho segundo Mateus (fólio 51 verso), uma "base linear" no final de Marcos

\footnotetext{
7 Parte dessa tradição cristã que atribuía os evangelhos a tais personagens foi colhida e registrada por Eusébio de Cesaréia em seu História Eclesiástica (HE. livro III, cap. 24), escrito no começo do século IV.
}

Horizonte, Belo Horizonte, v. 14, n. 42, p. 284-314, abr./jun. 2016 - ISSN 2175-5841 
(fólio 96 recto), um vaso invertido em Lucas (fólio 171 verso) e um triângulo invertido em João (fólio 225 recto) (PINHEIRO, 2002, p. 20-21).

Figura 2 - Fólio 52 verso - última página do Evangelho de Mateus no códice 2437.

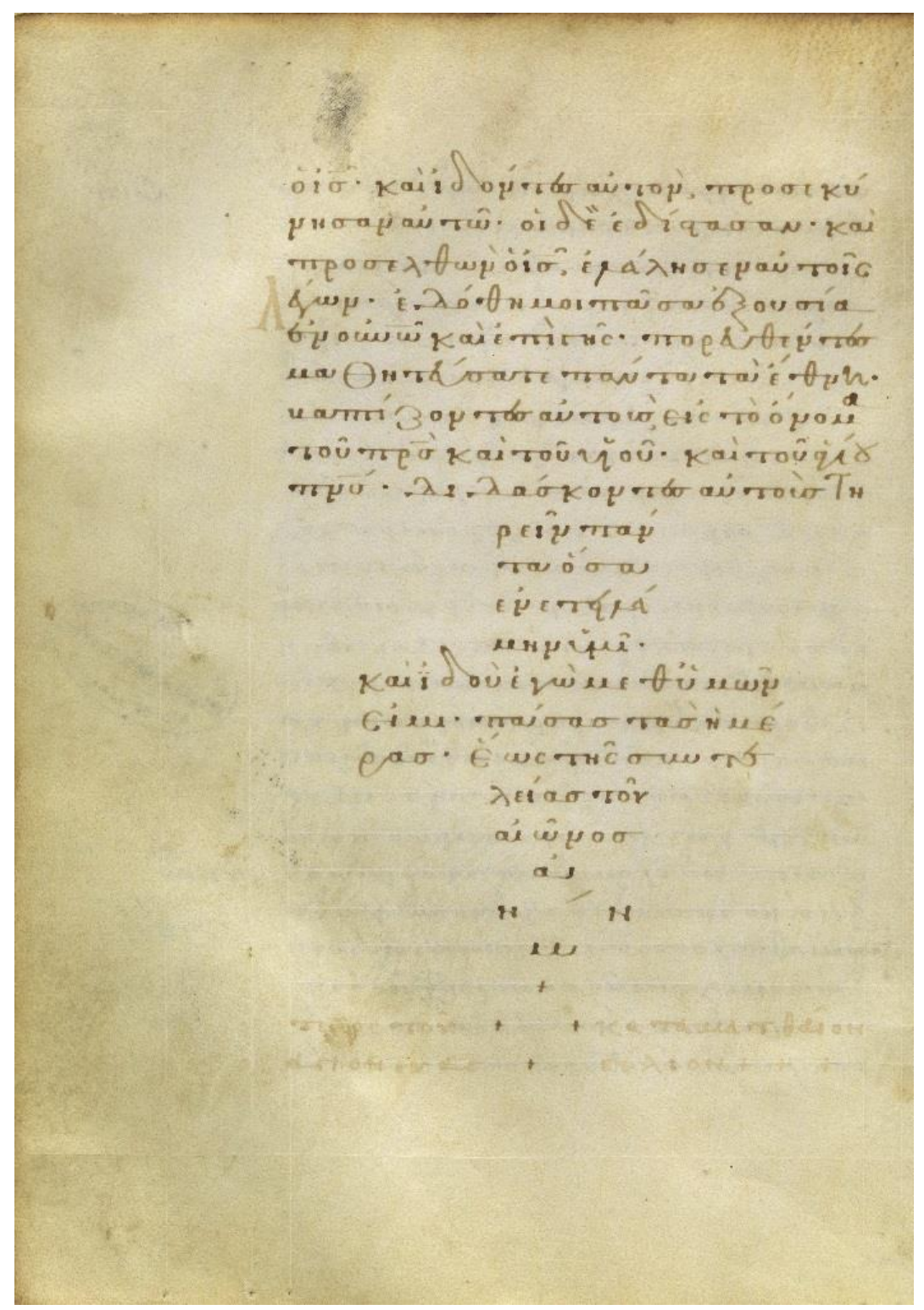

Fonte: Acervo da Fundação Biblioteca Nacional - Brasil (2015).

A identificação dos símbolos nem sempre é uma tarefa simples, quanto mais compreender que funções eles deveriam desempenhar nos atos de leitura. Ana Virgínia Pinheiro, após trabalhar na interpretação desses símbolos, escreveu: 
Invocando, apenas, uma experiência sensível, em face da escassez de bibliografia específica e porque a simbologia cristã constitui terreno particularmente delicado, é possível visualizar nos textos dispostos como imagens, no fim de cada Evangelho, algumas alfaias litúrgicas. (2002, p. 21).

Se ela estiver correta ao sugerir que a simbologia apresenta alfaias litúrgicas, poderemos concluir que o códice tenha sido produzido para, dentre outras finalidades, ser utilizado liturgicamente e, de modo especial, nas celebrações eucarísticas.

Os comentários a seguir partem das palavras que Ana Virgínia Pinheiro escreveu em sua pesquisa (PINHEIRO, 2002, 20-21), as quais foram acrescidas de algumas leituras complementares feitas para esse trabalho. Ainda assim, a interpretação que pudemos dar a cada um dos símbolos merece ser rotulada como provisória:

\subsubsection{A Cruz no Final do Evangelho segundo Mateus}

Pinheiro já sugeria em seu trabalho sobre o códice 2437 que a cruz invertida que encontramos na última página do Evangelho segundo Mateus poderia ser uma Cruz de São Pedro. Essa leitura não é implausível; a tradição cristã costuma vincular a memória do célebre apóstolo Pedro ao Evangelho de Mateus, especialmente porque nas páginas desse livro o personagem Pedro desempenha um papel de singular protagonismo em comparação com os demais discípulos de Jesus. Por conta disso muitos estudiosos que pesquisam as origens históricas das tradições literárias do proto-cristianismo dizem que o primeiro evangelho deve ter nascido numa região em que a memória do apóstolo Pedro tinha grande destaque. ${ }^{8}$ Há também uma lenda de origem desconhecida sobre a morte de Pedro, preservada até hoje pela tradição cristã, segundo a qual este apóstolo teria sido crucificado de

\footnotetext{
${ }^{8}$ Para comprovar o protagonismo de Pedro no Evangelho de Mateus pode-se comparar Mateus 16.13-20, passagem em que temos a famosa confissão de Pedro, com a versão da mesma narrativa no Evangelho de Marcos 8.27-30. Somente em Mateus, quando Pedro diz que Jesus é o Cristo, Jesus passa a elogiá-lo o chamando de bem-aventurado por ter alcançado tal revelação, e declara que sobre Pedro edificaria sua igreja. A maior parte dos pesquisadores diz que o Evangelho de Mateus deve ter nascido na cidade de Antioquia da Síria, onde a memória de Pedro adquirira grande prestígio ainda no primeiro século (LIMA, 2014, p. 30-38).
}

Horizonte, Belo Horizonte, v. 14, n. 42, p. 284-314, abr./jun. 2016 - ISSN 2175-5841 
cabeça para baixo em Roma, o que explicaria a posição invertida da cruz que vemos no códice 2437. Sobre essa lenda pode-se ler na clássica obra de Eusébio de Cesaréia (HE. livro III, cap. 1).

\subsubsection{A "Base Linear" do Evangelho segundo Marcos}

Ainda seguindo a leitura de Ana Virgínia Pinheiro a tal "base linear" que aparece no final do Evangelho segundo Marcos pode ser um prato (chamado de patena na Igreja ocidental) destinado à consagração do pão na liturgia eucarística. Pinheiro ainda sugere, mas de maneira mais insegura, uma relação entre o símbolo com o sacrifício de Jesus e sua vindicação, relacionando o símbolo ao conteúdo do evangelho com base em Marcos 14.

\subsubsection{O Cálice do Evangelho segundo Lucas}

O suposto cálice a que as últimas palavras do Evangelho de Lucas dão forma além de ser uma referência óbvia ao recipiente em que Jesus bebeu seu vinho na última ceia, também conhecido como o Graal, que por si só envolve uma grande tradição simbólica e mística (CIRLOT, 2001, p. 43), é um símbolo recorrente na cerimônia eucarística do cristianismo de modo geral. Se o símbolo realmente é um cálice, ele parece estar invertido, o que poderia simbolizar o "sangue derramado por vós”, conforme a interpretação de Pinheiro a partir de Lucas 22.20. De todo modo, a hipótese de uma ligação entre os símbolos e a cerimônia eucarística vai ficando mais forte.

\subsection{4 - O Triângulo do Evangelho segundo João}

O símbolo que aparece no final do Evangelho segundo João é um triângulo invertido, o que seria, segundo a pesquisa feita por Ana Virgínia Pinheiro, um símbolo para a água. Essa antiga simbologia parte da interpretação do hexagrama, a estrela de seis pontas que é formada por dois triângulos sobrepostos. Para a formação do hexagrama um desses dois triângulos estará necessariamente de 
cabeça para baixo e, neste contexto, simbolizaria a água ou a feminilidade (BIEDERMANN, 1993, p. 173). Se este for o caso do triângulo que fecha o Evangelho de João, não é difícil relacionar tal símbolo ao conteúdo do evangelho, que em dado momento apresenta metaforicamente a "água viva”, um valor eufórico ofertado pelo próprio Jesus àqueles que desejam não voltar a ter sede (João 3.1315).

De nossa parte não há motivos para questionar a leitura que Ana Virgínia Pinheiro nos deixou. Nosso objetivo ao apresentar suas conclusões com tão poucas novidades é aplicá-las ao nosso estudo sobre a leitura ideal do códice 2437, e nisso não poderemos nos esquivar da forte possibilidade de que o livro tenha sido produzido para uma finalidade específica, a leitura pública e ritual durante as celebrações eucarísticas da igreja cristã. Isso ajudaria a explicar com novos argumentos a produção de códices que, como o 2437, contém apenas os quatro evangelhos, pois são neles que se encontram as narrativas sobre a morte expiatória de Jesus, tema central das celebrações eucarísticas em todas as épocas.

\section{Considerações Finais}

Considerando conclusa a tarefa que propusemos, que era apresentar de maneira introdutória um novo caminho para o estudo da tradição bíblica manuscrita, encerramos aqui nosso primeiro artigo sobre o exame do códice 2437. Se estamos dizendo que ele é o primeiro pressupõe-se a futura publicação de outro(s). Reconhecemos que, embora já tenhamos demonstrado a possibilidade de se considerar o manuscrito de um ponto de vista que não é comum entre os biblistas, empregando uma crítica literária contemporânea que leva em conta a história do livro, o exame do códice que aqui expusemos tem que assumir um papel apenas inaugural. De fato, os itens apresentados nas últimas páginas (sejam aqueles com análises ou aqueles com a história da pesquisa do códice ou com o referencial teórico que escolhemos) são partes de um trabalho de pesquisa mais extenso. Para os próximos passos entendemos que será necessário lidar com o 
manuscrito de maneira mais direta e aprofundada em busca de conclusões mais precisas sobre os protocolos e as práticas de leituras implicadas no códice 2437. Assim sendo, justificando a interrupção abrupta de nossas análises, deixamos o convite ao leitor interessado para que nos acompanhe em páginas futuras.

\section{REFERÊNCIAS}

ALAND, Kurt; ALAND, Barbara. O texto do Novo Testamento: uma introdução às edições e à teoria e prática da moderna crítica textual. São Paulo: Fonte Editorial, 2009.

ALTER, Robert. A arte da narrativa bíblica. São Paulo: Companhia das Letras, 2007.

BRANDÃO, Jacyntho Lins. O códice 2437 do Novo Testamento grego (evangelho grego da Biblioteca Nacional do Rio de Janeiro). Ágora - Estudos Clássicos em Debate. Aveiro, v. 4, p. 39-56, 2002.

BENÍCIO, Paulo José. Características literárias e tendências manuscritológicas do Evangelho Segundo Marcos no códice 2437. Revista Philologus, Rio de Janeiro, ano 17, n. 49, p. 25-56, 2011.

BENÍCIO, Paulo José. Identificação, descrição e datação do códice grego neotestamentário da Biblioteca Nacional do Rio de Janeiro. Todas as Letras, São Paulo, v.6, n.1, p. 83-86, 2004 .

BIEDERMANN, Hans. Dictionary of symbolism: cultural icons and the meanings behind them. New York/Oxford: Facts on File, 1992.

CAVALLO, Guglielmo; CHARTIER, Roger (orgs.). História da leitura no mundo ocidental (vol. 1). São Paulo: Ática, 1998.

CHARTIER, Roger. A história ou a leitura do tempo. Belo Horizonte: Autêntica Editora, 2010.

CHARTIER, Roger. A mão do autor e a mente do editor. São Paulo: Editora UNESP, 2014.

CHARTIER, Roger. (org.). Práticas de leitura. São Paulo: Estação Liberdade, 2011.

CHARTIER, Roger. Materialidad del texto, textualidad del libro. Orbis Tertius, Buenos Aires, vol. 11, n. 12, p. 1-9, 2006.

CIRLOT, J. E. A dictionary of symbols. London: Routledge, 2001. 
CRAIN, Jeanie C. Reading the Bible as literature: an introduction. Malden: Polity Press, 2010.

DARNTON, Robert. O Beijo de Lamourette: mídia, cultura e revolução. São Paulo: Companhia das Letras, 2010.

ESTIBEIRA, Maria do Céu. Uma perspectiva da marginalia de Fernando Pessoa.

Patrimônio e Memória, Assis, v.6, n.1, p.129-145, 2010.

FRYE, Northrop. O código dos códigos: a Bíblia e a literatura. São Paulo: Boitempo, 2004.

FUNARI, Pedro Paulo Abreu. Arqueologia. São Paulo: Contexto, 2014.

FUNARI, Pedro Paulo Abreu. Os historiadores e a cultura material. In. PINSKY, Carla

Bassanezi (org.). Fontes históricas. São Paulo: Contexto, p. 81-110, p. 2011.

FUNARI, Pedro Paulo Abreu; CARVALHO, Aline Vieira de. Cultura material e patrimônio histórico: discussões atuais. In. Cultura material e patrimônio da ciência e

tecnologia. Rio de Janeiro: Museu de Astronomia e Ciências Afins (MAST), p. 3-13, 2009.

GOUMELOT, Jean Marie. Da leitura como produção de sentidos. In. CHARTIER, Roger

(org.). Práticas de leitura. São Paulo: Estação Liberdade, p. 107-116, 2011.

JACKSON, H. J. Marginalia: readers writing in books. New Haven/London: Yale University Press, 2001.

LIMA, Anderson de Oliveira. Bíblia e materialidade: o "Novo Testamento Interlinear" da Sociedade Bíblica como projeto editorial. Memento, Três Corações, v. 3, n. 2, p. 123-133, 2012.

LIMA, Anderson de Oliveira. Dois momentos na história recente da leitura bíblica: a Bíblia como literatura a partir de Erich Auerbach e Robert Alter. Teoliterária, São Paulo, vol. 4, n. 7, p. 131-150, 2014a.

LIMA, Anderson de Oliveira. O autor como personagem implícito na teoria literária e as particularidades autorais das narrativas bíblicas. Orácula, São Paulo, ano 10, n. 15, p. 74$88,2014 \mathrm{~b}$.

LIMA, Anderson de Oliveira. Reações literárias à cultura de reciprocidade do antigo mundo mediterrâneo: uma leitura da linguagem econômica do Evangelho de Mateus. Tese (Doutorado em Ciências da Religião). São Bernardo do Campo: Universidade Metodista de São Paulo, 2014.

MENESES, Ulpiano T. Bezerra de. A cultura material no estudo das sociedades antigas. Revista de História, São Paulo, n. 115, p. 103-117, 1983.

METZGER, Bruce M. Um manuscrito grego dos quatro evangelhos na Biblioteca Nacional do Rio de Janeiro. Revista Teológica do Seminário Presbiteriano do Sul, Campinas, n. II, nova fase, p. 5-9, 1952. 
MILES, Jack. Deus, uma biografia. São Paulo: Companhia das Letras, 2009.

NESTLE, Eberhard; ALAND, Kurt. Novum Testamentum Graece. Stuttgart, Deutsche Bibelgesellschaft, $27^{\mathrm{a}}$ ed. 1993.

PAROSCHI, Wilson. Crítica textual do Novo Testamento. São Paulo: Vida Nova, 1993.

PINHEIRO, Ana Virgínia. O evangelho manuscrito em grego existente no acervo da Biblioteca Nacional Brasileira: aspectos codicológicos. Anais da Biblioteca Nacional. Rio de Janeiro: Biblioteca Nacional, 1998, v. 118, p. 7-33, 2002.

SARAIVA, Maria Olívia de Quadros. O Evangelho de Lucas no manuscrito grego da Biblioteca Nacional do Rio de Janeiro (cód. 2437): edição e glossário. Tese (Doutorado em Linguística Teórica e Descritiva) - Universidade Federal de Minas Gerais, Belo Horizonte, 2011.

SARAIVA, Maria Olívia de Quadros. O Evangelho de Mateus no manuscrito grego da Biblioteca Nacional do Rio de Janeiro (folha 24 recto - Mt, 18:32-35; 19:1-5). Scripta Classica On-Line. Literatura, Filosofia e História na Antiguidade. N. 1, 2003.

SARAIVA, Maria Olívia de Quadros; BARBOSA, Tereza Virginia Ribeiro. Manuscrito grego 2437 da Biblioteca Nacional: pesquisas desenvolvidas de 1952 a 2012. Belo Horizonte: Fino Traço, 2012.

SILVA, Loide Melo de Araújo. Evangelho de João no códice 2437: um estudo críticotextual. Tese (Doutorado em Teoria Literária e Literaturas) - Universidade de Brasília, 2008. 